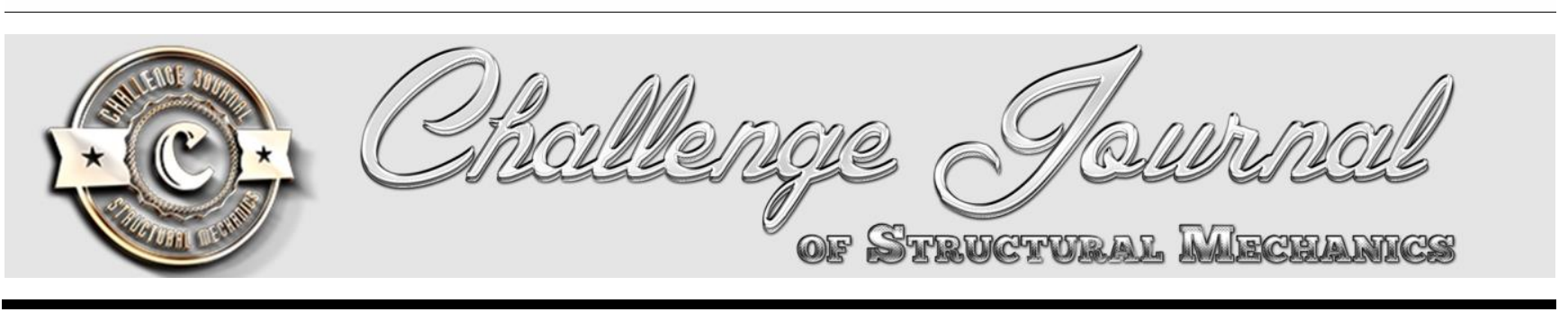

\title{
Seismic performance evaluation of an existing school building in Turkey
}

\author{
Hüseyin Bilgin * \\ Department of Civil Engineering, Epoka University, 1039 Tirana, Albania
}

\section{ABS T RAC T}

A great part of existing RC structures built in Turkey is that they have been designed without considering seismic-induced actions and seismic criteria for strength and ductility design. In this context, after the recent devastating earthquakes in Turkey, there has been a concerted effort to address the seismic vulnerability of existing public buildings in Turkey. The need for the evaluation and strengthening of these public buildings have come into focus following the enormous loss of lives and property during the past earthquakes. This study aims to assess the seismic performance evaluation of a typical school building in accordance with the rules of Turkish Earthquake Code-2007. The performance analysis is carried out by using nonlinear static analysis. The analytical solutions show that the intended performance level has not been satisfied for this building and decided to retrofit the structural system. The proposed procedure is applied to the retrofitted system and the obtained results are tabulated and discussed.
\end{abstract}

\section{ARTICLE INFO}

Article history:

Received 11 May 2015

Accepted 2 July 2015

Keywords:

Public buildings

Performance evaluation

Pushover analysis

Retrofit

\section{Introduction}

Earthquakes are of concern to cities in Turkey. Because many existing structures in this region are inadequate based on the current seismic design codes, it is important to assess these structures and improve the seismic resistance of systems that are found to be vulnerable. In general, buildings designed without seismic considerations have significant deficiencies such as discontinuity of positive moment reinforcement in beams and wide spacing stirrups. Besides the design deficiencies poor quality material and workmanship are the other important factors.

The projects and the construction of existing public buildings that were built before 1998, were constructed in accordance with the regulations Turkish Building Code-1984, (TBC-1984) and Turkish Earthquake Code, (TEC-1975), which were in effect at that time. However, the earthquake and the construction regulations underwent significant changes with the revisions made in 1998, 2000 and 2007 (TEC-1998, TBC-2000, TEC-2007). The strengthening of existing public buildings in conjunction with new contract specifications, thereby reducing loses of life and property to a minimum in case of an earthquake has become one of the most important issues on the agenda of Turkish Government. In addition, a number of major earthquakes during the last two decades have underlined the importance of mitigation to reduce seismic risk.

Seismic strengthening of existing structures is one method to reduce the risk to vulnerable structures. Recently, a significant amount of research has been devoted to the study of various retrofit techniques to enhance the seismic performance of RC structures (ASCE/SEI 41-06, Eurocode 8, FEMA 356, and FEMA 440). However, few studies have been conducted to assess the seismic performance of representative concrete structures in Turkey using the criteria of Turkish Earthquake Code-2007 (TEC-2007).

The accepted analysis procedures in the analysis include two types of linear elastic methods: equivalent lateral force analysis and modal response spectrum analysis, and two type of nonlinear methods: pushover analysis, and non-linear time history analysis. Since force based approaches have some shortcomings for seismic evaluation, displacement based design procedures are used. Linear-elastic methods have some shortcomings, since they aimed to provide a conservative estimate of building performance during an earthquake. Response of buildings to earthquakes is not typically linear; hence

*Corresponding author. Tel.: +355-4-2232086 ; Fax: +355-4-2222177 ; E-mail address: hbilgin@epoka.edu.al (H. Bilgin) 
convenient nonlinear analysis methods should provide a good representation of buildings' response and performance. When nonlinear methods are used, since performance limits on permissible response are less-conservative than the linear elastic ones, lower construction costs may be fulfilled. Structural performance of the existing buildings are determined by applying nonlinear static procedures defined in most earthquake design codes; ATC-40, FEMA-356, Turkish Earthquake Code-2007 (TEC-2007).

\section{Turkish Earthquake Codes}

The earthquake resistance consideration for building design in Turkey has a history of more than fifty years. Beginning as legal provision in mid 1940's after a series of destroying earthquakes, Turkey's earthquake code is developed to its present state in 2007 after a number of evolutionary revisions respectively in 1959, 1975, 1998. The final version of the code includes regulations on repairing and retrofitting existing buildings (Chapter 7). Chapter 7 of TEC-2007 has many similarities to the new modern codes (ATC-40, FEMA-356, Eurocode 8, etc) consists of linear and nonlinear methods to evaluate the seismic performance of existing buildings.

\section{Structural Properties of the Analyzed School Building}

Schools likewise the other buildings intended for governmental services are generally constructed by applying template designs developed by the Ministry of Public Works. Therefore, a considerable number of buildings have the same template designs in different parts of Turkey.

A field survey was carried out in the western part of Turkey to select the most common types of school buildings. These cities are located in a seismically active part of Turkey. According to the survey, a most common type of template design (TD-10419) for school buildings was selected to represent these public buildings in mediumsized cities.

This is a four-story school building with a plan area of 613 square meters at the base. All floor slabs are reinforced concrete with a thickness of $0.2 \mathrm{~m}$. The story heights are $3.4 \mathrm{~m}$ for each story. There exists no exact data about the roofing and the masonry partitions of the building. From the architectural drawing plotted at the time of construction, reasonable values are assumed for both in dead load and other calculations, considering probable changes made during the construction.

The building has a typical structural system, which consists of reinforced concrete frames with masonry infill walls of hollow clay brick units. The structural system is free of shear walls in longitudinal direction and composed of shear wall-frame system in transverse direction. There are no structural irregularities such as soft story, weak story, heavy overhangs, great eccentricities between mass and stiffness centers. One of the possible deficiencies for this building designed per TEC-1975 is the strong beam-weak column behavior as it is not regarded by that code. Fig. 1 and Fig. 2 provide a typical floor plan and 3-D view of this case study structure respectively.

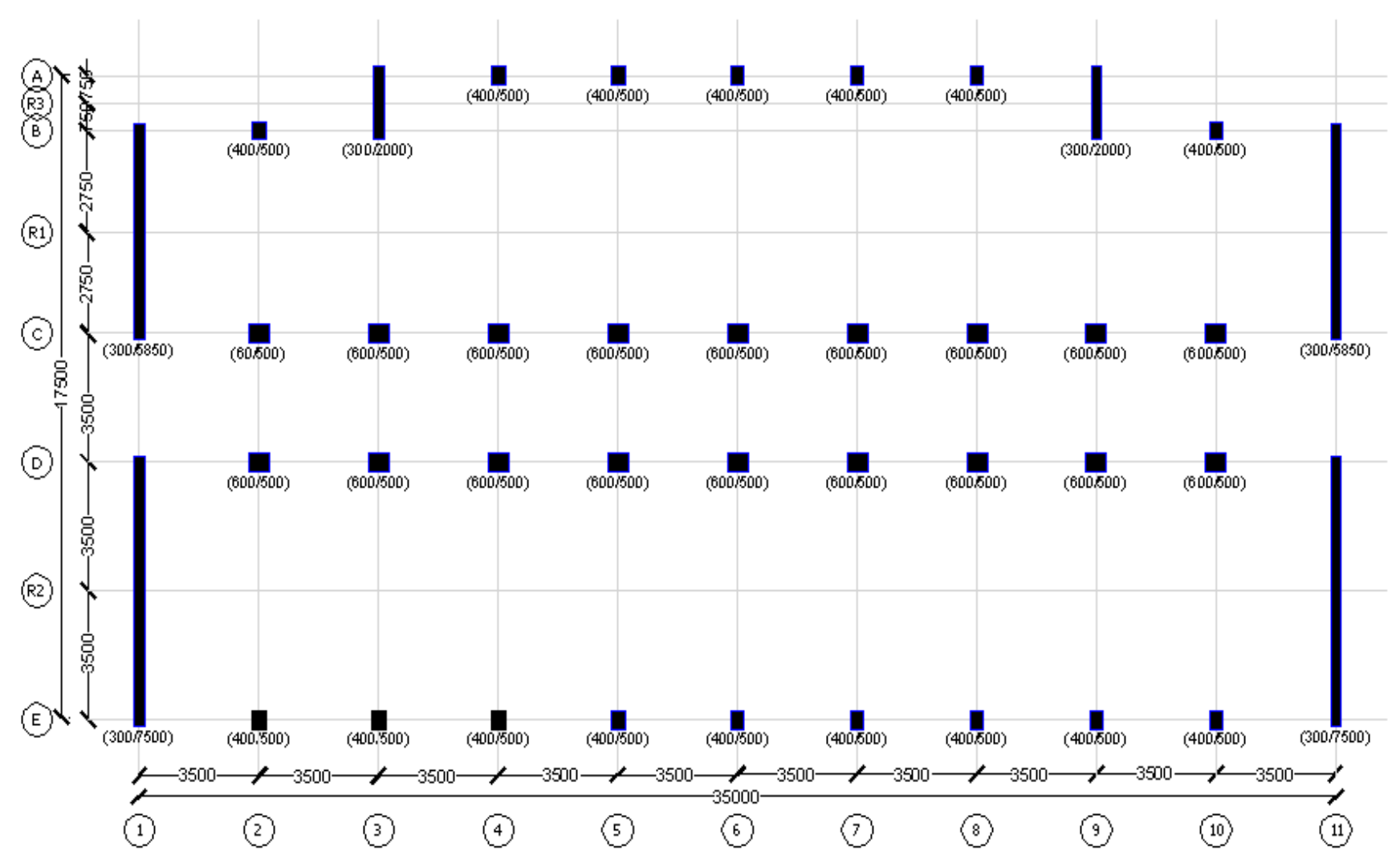

Fig. 1. Typical structural floor plan view of the TD-10419 building. 


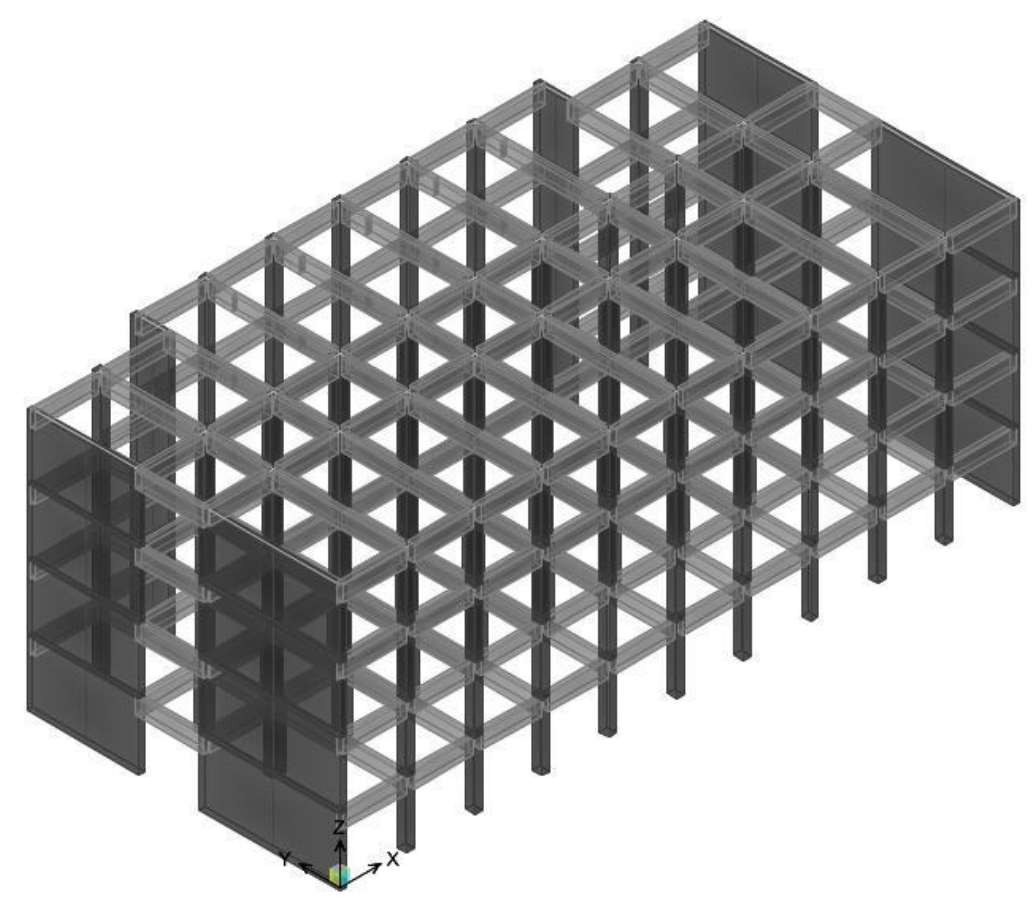

Fig. 2. Three dimensional view of the TD-10419 building.

\section{Analytical Modeling of the School Building}

\subsection{Analytical modeling}

SAP2000 (CSI, 2003) is employed for the modeling and analysis of the structure. The building is modeled as 3-D frame-shear wall system formed by beams, columns and shear walls. The joints connecting the base columns and shear walls to the foundation are restrained for all degrees of freedom. The calculation of the masses, dead and live loads are made according to the Turkish Standards for Reinforced Concrete (TBC-2000), Turkish Standards for Design Loads (TS-498) and TEC-1975.

For nonlinear analysis, as-built material properties determined from field investigation and experiment are taken into account. Modeling properties of the investigated building is tabulated in Table 1 .

Table 1. Structural properties of the investigated building.

\begin{tabular}{cc}
\hline & TD10419 \\
\hline Number of stories & 4 \\
Story height (m) & 3.4 \\
Floor area $\left(\mathrm{m}^{2}\right)$ & 612.5 \\
Total building weight $(\mathrm{t})$ & 3323 \\
Concrete Class & C10, C16 \\
Steel Grade & S220 \\
$\begin{array}{c}\text { Stirrup spacing at the plastic } \\
\text { hinge locations (mm) }\end{array}$ & 150 and 250 \\
$X$ - period (s) & 0.54 \\
$Y$ - period $(\mathrm{s})$ & 0.24 \\
$\begin{array}{c}\text { Mass participation ratios in } \\
x \text { - and } y \text {-, respectively }\end{array}$ & $0.86-0.75$ \\
\hline
\end{tabular}

\subsection{Determination of nonlinear parameters}

Member size and reinforcements in the template design are used to model the school building for nonlinear analysis. The structural modelling is carried out with the beam, column and shear wall elements, considering the nonlinear behaviour concentrated in plastic hinges at both ends of beams and columns. SAP2000 provides default or the user-defined hinge properties options to model nonlinear behaviour of components. In this study, user-defined hinge properties are used.

The definition of user-defined hinge properties requires moment-curvature relationships for beams and columns and axial force moment capacity data for the columns are necessary for the SAP2000 input as nonlinear properties of elements (Fig. 3).

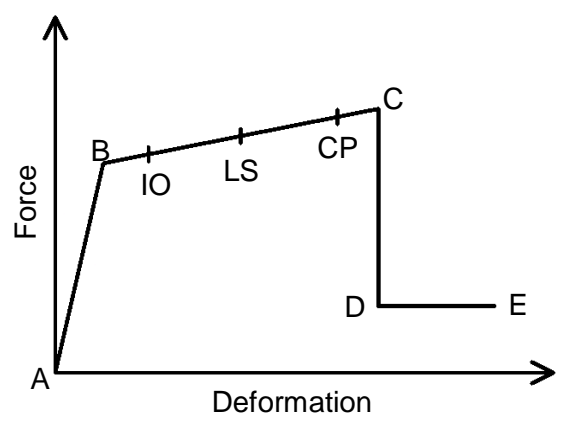

Fig. 3. Typical force deformation relationship.

Mander model (Mander el al., 1988) is used for unconfined and confined concrete while typical steel stressstrain model with strain hardening for steel is implemented in moment-curvature analyses. The input required for SAP2000 is moment-rotation relationship instead of moment-curvature. Also, moment rotation data 
have been reduced to five-point input that brings some inevitable simplifications. Plastic hinge length is used to obtain ultimate rotation values from the ultimate curvatures. Plastic hinge length definition given in Eq. (1) which is proposed by Priestley et al. (1996) is used in this study.

$$
L_{p}=0.008 L+0.022 f_{y e} d_{b l} \geq 0.044 f_{y e} d_{b l} .
$$

In Eq. (1), $L_{p}$ is the plastic hinge length, $\mathrm{L}$ is the distance from the critical section of the plastic hinge to the point of contraflexure, $f_{y e}$ and $d_{b l}$ are the expected yield strength and the diameter of longitudinal reinforcement.

In existing reinforced concrete buildings, especially with low concrete strength and insufficient amount of transverse steel, shear failures of members should be taken into consideration. For this purpose, shear hinges are introduced for beams and columns. Shear hinge properties are defined such that when the shear force in the member reaches its shear strength, member immediately fails. The shear strength of each member $\left(V_{r}\right)$ is calculated according to TBC- 2000.

$V_{r}=0.182 b d \sqrt{f_{c}}+\left(1+0.07 \frac{N}{A_{c}}\right)+\frac{A_{s h} f_{y h d}}{S}$.

In Eq. (2), $b$ is section width, $d$ is effective section depth, $f_{c}$ is concrete compressive strength, $N$ is compression force on section, $A_{c}$ is area of section, $A_{s h}, f_{y h}$ and $s$ are area, yield strength and spacing of transverse reinforcement.

\section{Performance Evaluation of the School Building by Using Pushover Analysis}

In order to apply this method, TEC-2007 requires some limitations on the building height ad torsional irregularity and the mass participation ratios for the first mode. Pursuant to TEC-2007, mass participation ratios must be greater than $70 \%$. For the addressed building, this value is $86 \%$ in $x$-direction more than proposed.

The pushover analysis consists of the application of gravity loads and a lateral load pattern. The applied lateral forces are proportional to the product of mass and the first mode shape amplitude at each story level and P$\Delta$ effects are taken into account.

In the capacity curve plots, base shear is normalized by building seismic weight on the vertical axis, while global displacement drift is normalized by building height on the horizontal axis. Capacity curves of the school building is obtained for different concrete strength and transverse reinforcement spacing mentioned in previous section; two concrete strength and two transverse reinforcement spacing values are taken into account.

Two extreme cases are considered in order to have a more accurate understanding in the boundaries of behavior for the case study building with the considered template design. The first one represents the buildings in poor condition having poor concrete quality (10 $\mathrm{MPa})$ with non-ductile detailing $(250 \mathrm{~mm}$ transverse rein- forcement spacing). The second one refers to the buildings in average condition having average concrete quality (16 MPa) with ductile detailing $(150 \mathrm{~mm}$ transverse reinforcement spacing). Capacity curves corresponding to poor and average conditions are illustrated in Fig. 4 for longitudinal $(x)$ and transverse $(y)$ directions.
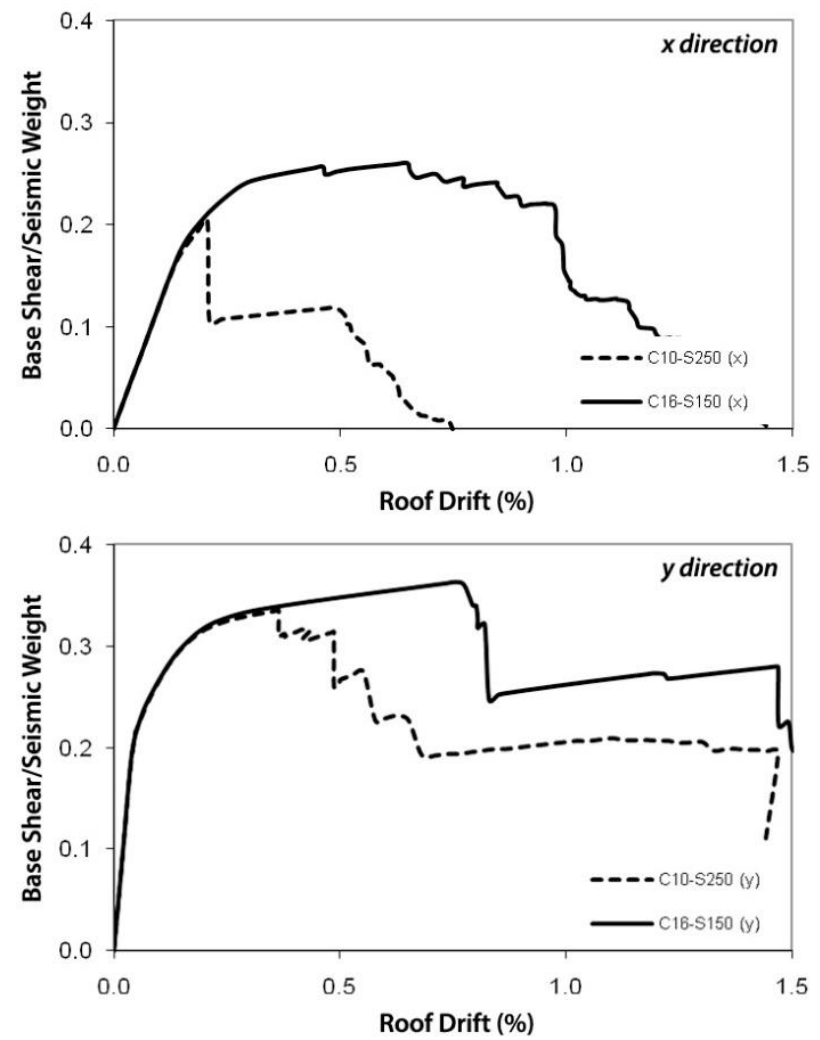

Fig. 4. Capacity curves of the building TD-10419 for different concrete strength and transverse reinforcement spacing obtained by pushover analysis.

Evaluation of the capacity curves for the investigated building points out that concrete quality and detailing has significant role in both displacement and lateral strength capacity of buildings. The displacement capacity for the average condition is more than twice of that for poor condition.

\subsection{Performance evaluation according to TEC-2007}

Capacity assessment of the investigated school building is performed using TEC-2007. Three performance levels, immediate occupancy (IO), life safety (LS), and collapse prevention (CP) are considered as specified in this code and several other international guidelines such as FEMA-356, ATC-40, and FEMA-440.

Pushover analysis data and criteria of TEC-2007 are used to determine global displacement drift ratio of each building corresponding to the performance levels considered. Table 2 lists global displacement drift ratios of the building. Small displacement capacities at LS and CP performance levels are remarkable for the building with poor concrete quality and less amount of transverse reinforcement due to shear failures in columns (C10-S250). 
The displacement capacity values are solely not meaningful themselves. They need to be compared with demand values. According to the Turkish Earthquake Code, school buildings are expected to satisfy IO and LS performance levels under design and extreme earthquakes, corresponding to $10 \%$ and $2 \%$ probability of exceedance in 50 years, respectively. Response spectrum for the design and extreme earthquakes is plotted in Fig. 5 for high seismicity region and soil class Z3. Displacement demand estimates and capacities corresponding to IO and LS performance levels are compared.

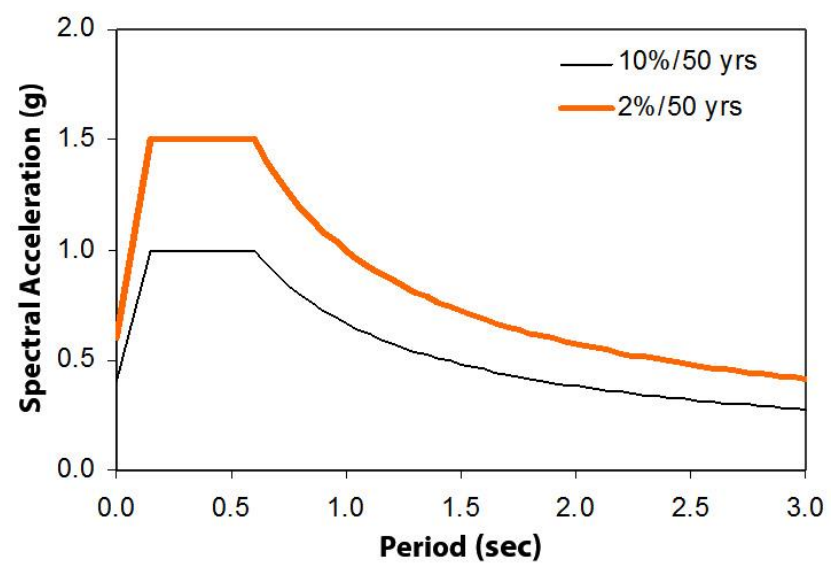

Fig. 5. Response spectrum for design and extreme earthquake events provided in TEC-2007.

Displacement demand estimates are obtained (Table 3) as described in TEC-2007. The results obtained show that school building does not provide IO in both directions whereas LS performance level is satisfied in $y$ - direction which means that the structural system should be strengthened.

\subsection{Performance evaluation according to TEC-2007}

As it is seen that existing structural system of the school building does not satisfy the expected performance levels and it is decided to strength the structural system. For strengthening, shear walls are added to the existing structural system of the building. Six in $x$ - direction and one in $y$ - shear walls are added to the existing structural system (Fig. 6). The material classes for reinforced concrete shear walls are considered to be C25 $\left(f_{c k}=25 \mathrm{MPa}\right)$ and S420 $\left(f_{y k}=420 \mathrm{MPa}\right)$.

The 3-D model of the new system is analyzed by SAP2000. The first and second mode periods in $x$ - and $y$ directions are found to be $0.28 \mathrm{~s}$ and $0.19 \mathrm{~s}$, respectively. As it is seen that the while the stiffness increases, fundamental vibration period decreases. Similar performance evaluation procedure for existing structural system is repeated for new system. Pushover curves for the new and existing are given in Fig. 7.

Capacity assessment and seismic displacement demand calculations are repeated for the new structural system according to TEC-2007 and the results are tabulated in Table 4.

Obtained results show that strengthened school building satisfies IO performance levels under the design earthquake and provides LS performance level under maximum earthquake.

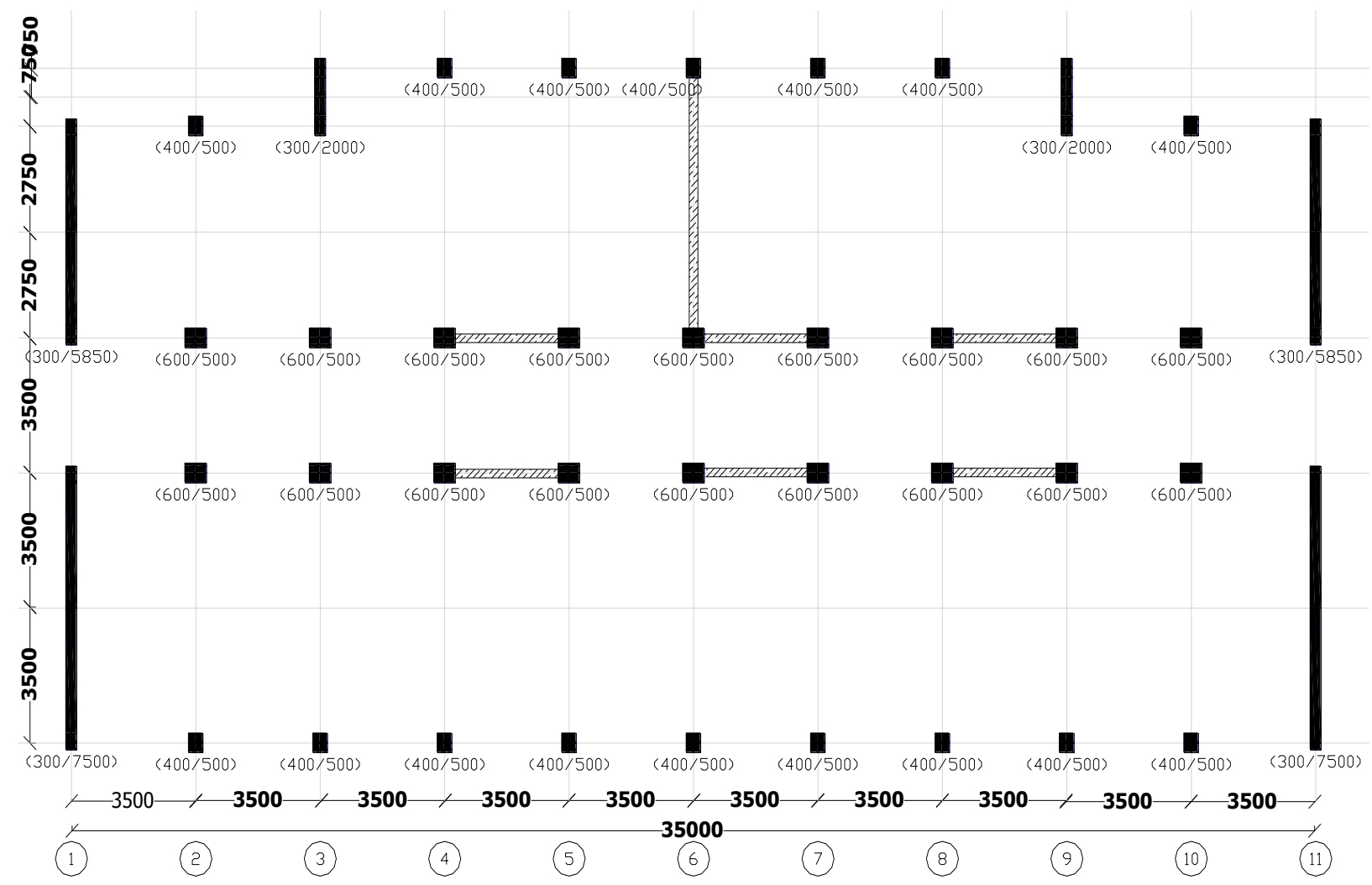

Fig. 6. Structural floor plan view of strengthened TD-10419 building. 
Table 2. Global displacement drift capacities (\%) of the investigated building obtained from capacity curves for considered performance levels.

\begin{tabular}{|c|c|c|c|c|}
\hline \multirow{3}{*}{$\begin{array}{c}\text { Material } \\
\text { Quality }\end{array}$} & \multicolumn{4}{|c|}{$\Delta_{\text {roof }} / H_{\text {building }}$} \\
\hline & \multicolumn{2}{|c|}{$x$-direction } & \multicolumn{2}{|c|}{$y$-direction } \\
\hline & IO & LS & IO & LS \\
\hline C10-S150 & 0.16 & 0.40 & 0.16 & 0.47 \\
\hline C10-S250 & 0.16 & 0.19 & 0.14 & 0.36 \\
\hline C16-S150 & 0.19 & 0.52 & 0.23 & 0.55 \\
\hline C16-S250 & 0.17 & 0.25 & 0.21 & 0.51 \\
\hline
\end{tabular}

Table 3. Global demand drift ratios (\%) of the investigated building according to TEC-2007.

\begin{tabular}{llll}
\hline \multicolumn{4}{c}{$\Delta_{\text {roof }} / H_{\text {building }}$} \\
\hline \multicolumn{3}{c}{$x$-direction } & \multicolumn{3}{c}{$y$-direction } \\
IO & LS & IO & LS \\
\hline 0.76 & 1.15 & 0.28 & 0.46 \\
\hline
\end{tabular}
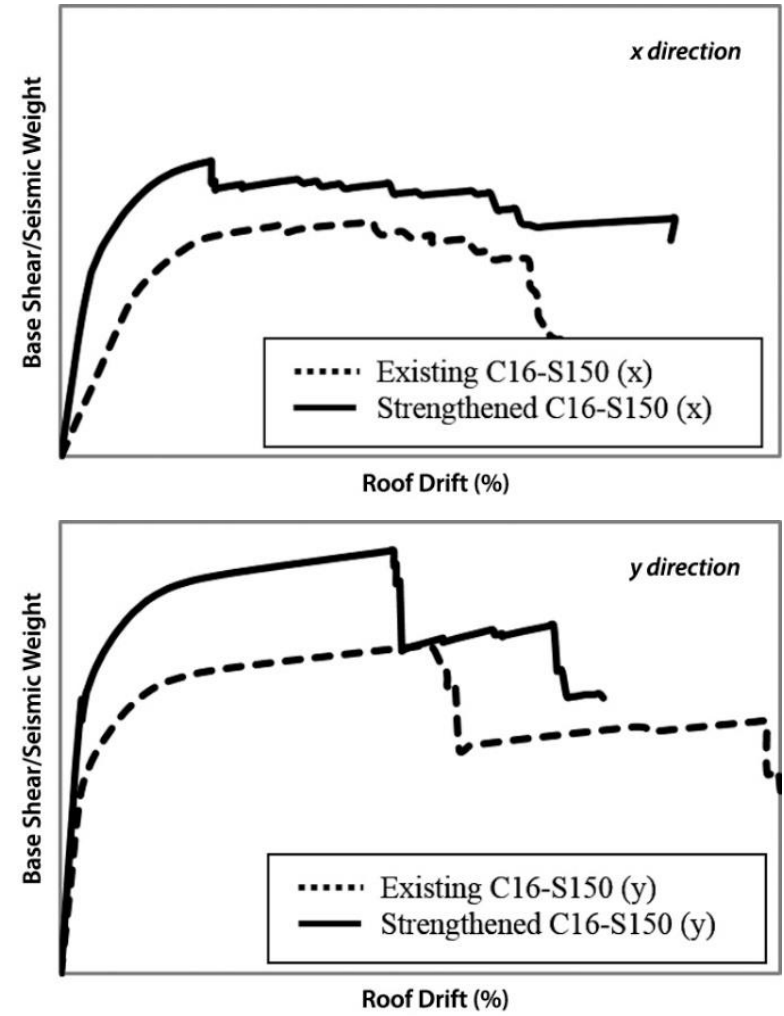

Fig. 7. Capacity curves of the strengthened school building obtained by pushover analysis.

Table 4. Comparison of global displacement drift capacities and global drift demand ratios of the investigated school building for considered performance levels according to TBC-2007(\%).

\begin{tabular}{|c|c|c|c|c|c|c|c|c|}
\hline \multirow{4}{*}{$\begin{array}{c}\text { Material } \\
\text { Quality }\end{array}$} & \multicolumn{8}{|c|}{$\Delta_{\text {roof }} / H_{\text {building }}$} \\
\hline & \multicolumn{4}{|c|}{$x$-direction } & \multicolumn{4}{|c|}{$y$-direction } \\
\hline & \multicolumn{2}{|c|}{ IO } & \multicolumn{2}{|c|}{ LS } & \multicolumn{2}{|c|}{ IO } & \multicolumn{2}{|c|}{ LS } \\
\hline & Demand & Capacity & Demand & Capacity & Demand & Capacity & Demand & Capacity \\
\hline C10-S250 & 0.38 & 0.38 & 0.60 & 0.97 & 0.21 & 0.24 & 0.36 & 0.36 \\
\hline C16-S150 & 0.36 & 0.37 & 0.59 & 1.05 & 0.20 & 0.27 & 0.35 & 0.38 \\
\hline
\end{tabular}

\section{Conclusions}

In this study, seismic performance assessment of an existing school building with the selected template design is studied according to TEC-2007. SAP2000 is employed for modeling and analyzing of the building. Existing structural system is evaluated by nonlinear methods to evaluate the performance levels. Analytical solutions have shown that the structural system of the school building does not satisfy the intended criteria in TEC2007. To strengthen the structural system, shear walls are added in $x$ - and $y$-directions. In order to find the economical solution for the new strengthening system, nonlinear analyses are repeated with different number of shear wall options. Performance evaluation for each analyses result has been done for the new system and the most appropriate strengthened system is proposed. The following conclusions can be drawn from numerical results:
- Based upon site investigation and laboratory test results; two strength values, 10 and $16 \mathrm{MPa}$, are considered for concrete and Grade 220 considered for reinforcement in this study.

- Two stirrup spacing values are considered as 150 and $250 \mathrm{~mm}$ to reflect ductile and non-ductile detailing, respectively.

- Evaluation of the capacity curves for the investigated building points out that concrete quality and detailing has significant role in displacement and lateral strength capacity of buildings in both directions. Although the difference of poor (C10 and s250) and average (C16 and s150) conditions on lateral strength capacity is limited, the difference in displacement capacity is noteworthy.

- Shear failures of columns are common problems in case of poor concrete and low amount of transverse reinforcement, resulting in brittle failure for existing school buildings. 
- As material quality gets better, performance of buildings improves. The displacement capacities obtained for different performance levels evidently indicates that concrete quality and transverse reinforcement spacing have limited effect on IO level while amount of transverse reinforcement plays an important role in seismic performance of buildings for LS level.

- According to TEC-2007, school buildings are expected to satisfy IO and LS performance levels under design and extreme earthquakes. The existing school building is far from satisfying the expected performance levels; therefore it is strengthened by adding shear walls in both directions. After retrofitting desired performance levels are provided in both directions.

- Addition of shear walls increases lateral load capacity and decreases displacement demands significantly. Thus, existing deficiencies in frame elements are less pronounced and poor construction quality in buildings is somehow compensated (Bilgin, 2007).

\section{REFERENCES}

ASCE/SEI 41-06 (2007). Seismic Rehabilitation of Existing Buildings. American Society of Civil Engineers, Reston, VA, USA.

ATC-40 (1996). Seismic Evaluation and Retrofit of Concrete Buildings (Volume 1-2). Applied Technology Council, Redwood City, CA, USA

Bilgin H (2007). Seismic Performance Evaluation of Public Buildings Using Non-Linear Analysis Procedures and Solution Methods. Ph.D. thesis, Pamukkale University, Turkey.
Eurocode-8 (2005). Design of Structures for Earthquake Resistance Part 3: Assessment and Retrofitting of Buildings. European Committee for Standardization, Brussels, Belgium.

FEMA-273 (1997). NEHRP Guidelines for the Seismic Rehabilitation of Buildings. American Society of Civil Engineers, Federal Emergency Management Agency, Washington, USA.

FEMA-356 (2000). Prestandard and Commentary for the Seismic Rehabilitation of Buildings. American Society of Civil Engineers, Federal Emergency Management Agency, Washington, USA.

FEMA-440 (2005). Improvement of Nonlinear Static Seismic Procedures. American Society of Civil Engineers, Federal emergency management agency, Washington, USA.

Mander JB, Priestly MJN, Park R (1988). Theoretical stress-strain model for confined concrete. ASCE Journal of Structural Division, 114(8), 1804-1826.

Priestley MJN, Seible F, Calvi GMS (1996). Seismic Design and Retrofit of Bridges. John Wiley \& Sons, New York.

SAP2000 (2003). Integrated Finite Element Analysis and Design of Structures. Computers and Structures Inc., Berkeley, California.

TBC-1984 (1984). Requirements for Design and Construction of Reinforced Concrete Structures. Ankara, Turkey.

TBC-500 (2000). Requirements for Design and Construction of Reinforced Concrete Structures. Ankara, Turkey.

TEC-1975 (1975). Regulations on Structures Constructed in Disaster Regions. Ministry of Public Works and Settlement, Ankara, Turkey.

TEC-1998 (1998). Specifications for Structures to be built in Disaster Areas. Ministry of Public Works and Settlement, Ankara, Turkey.

TEC-2007 (2007). Turkish Earthquake Code: Regulations on Structures Constructed in Disaster Regions. Ministry of Public Works and Settlement, Ankara, Turkey.

TS-498 (1997). Design Loads for Buildings. Turkish Standard Institute, Ankara, Turkey. 